\title{
Convergence theorems of common fixed points for some semigroups of nonexpansive mappings in complete CAT(0) spaces
}

\author{
Lai-Jiu Lin ${ }^{1 *}$, Chih-Sheng Chuang ${ }^{1}$ and Zenn-Tsun Yu²
}

\section{"Correspondence:}

maljlin@cc.ncue.edu.tw

'Department of Mathematics,

National Changhua University of

Education, Changhua, 50058,

Taiwan

Full list of author information is

available at the end of the article

\begin{abstract}
In this paper, we consider some iteration processes for one-parameter continuous semigroups of nonexpansive mappings in a nonempty compact convex subset $C$ of a complete CAT(0) space $X$ and prove that the proposed sequence converges to a common fixed point for these semigroups of nonexpansive mappings. Note that our results generalize Cho et al. result (Nonlinear Anal. 74:6050-6059, 2011) and related results.
\end{abstract}

Keywords: common fixed point; CAT(0) space; nonexpansive semigroup; implicit iteration process

\section{Introduction}

Fixed point theory in CAT(0) spaces was first studied by Kirk [1, 2]. He showed that every nonexpansive (single-valued) mapping defined on a bounded closed convex subset of a complete CAT(0) space always has a fixed point. Since then, the fixed point theory for single-valued and multivalued mappings in CAT(0) spaces has been rapidly developed, and many papers have appeared; for example, one can see [3-6] and related references.

Let $(X, d)$ be a metric space. A geodesic path joining $x \in X$ to $y \in X$ (or, more briefly, a geodesic from $x$ to $y$ ) is a map $c$ from a closed interval $[0, \ell] \subseteq R$ to $X$ such that $c(0)=x$, $c(\ell)=y$, and $d\left(c(t), c\left(t^{\prime}\right)\right)=\left|t-t^{\prime}\right|$ for all $t, t^{\prime} \in[0, \ell]$. In particular, $c$ is an isometry and $d(x, y)=\ell$. The image $\alpha$ of $c$ is called a geodesic (or metric) segment joining $x$ and $y$. When it is unique, this geodesic is denoted by $[x, y]$. The space $(X, d)$ is said to be a geodesic space if every two points of $X$ are joined by a geodesic, and $X$ is said to be uniquely geodesic if there is exactly one geodesic joining $x$ and $y$ for each $x, y \in X$. A subset $Y \subseteq X$ is said to be convex if $Y$ includes every geodesic segment joining any two of its points.

A geodesic triangle $\Delta\left(x_{1}, x_{2}, x_{3}\right)$ in a geodesic space $(X, d)$ consists of three points $x_{1}$, $x_{2}$, and $x_{3}$ in $X$ (the vertices of $\Delta$ and a geodesic segment between each pair of vertices (the edge of $\Delta)$ ). A comparison triangle for geodesic triangle $\Delta\left(x_{1}, x_{2}, x_{3}\right)$ in $(X, d)$ is a triangle $\bar{\Delta}\left(x_{1}, x_{2}, x_{3}\right):=\Delta\left(\bar{x}_{1}, \bar{x}_{2}, \bar{x}_{3}\right)$ in the Euclidean plane $\mathbb{E}_{2}$ such that $d_{\mathbb{E}_{2}}\left(\bar{x}_{i}, \bar{x}_{j}\right)=d\left(x_{i}, x_{j}\right)$ for $i, j \in\{1,2,3\}$.

A geodesic space is said to be a CAT(0) space if all geodesic triangles of appropriate size satisfy the following comparison axiom.

CAT(0): Let $\Delta$ be a geodesic triangle in $X$, and let $\bar{\Delta}$ be a comparison triangle for $\Delta$. Then $\Delta$ is said to satisfy the $\operatorname{CAT}(0)$ inequality if for all $x, y \in \Delta$ and all comparison points

(c) 2012 Lin et al: licensee Springer. This is an Open Access article distributed under the terms of the Creative Commons Attribution License (http://creativecommons.org/licenses/by/2.0), which permits unrestricted use, distribution, and reproduction in any medium, provided the original work is properly cited. 
$\bar{x}, \bar{y} \in \bar{\Delta}, d(x, y) \leq d_{\mathbb{E}_{2}}(\bar{x}, \bar{y})$. It is well known that any complete, simply connected Riemannian manifold having nonpositive sectional curvature is a CAT $(0)$ space. Other examples include pre-Hilbert spaces [7], R-trees [8], the complex Hilbert ball with a hyperbolic metric [9], and many others.

If $x, y_{1}, y_{2}$ are points in a CAT(0) space, and if $y_{0}$ is the midpoint of the segment $\left[y_{1}, y_{2}\right]$, then the $\mathrm{CAT}(0)$ inequality implies

$$
d^{2}\left(x, y_{0}\right) \leq \frac{1}{2} d^{2}\left(x, y_{1}\right)+\frac{1}{2} d^{2}\left(x, y_{2}\right)-\frac{1}{4} d^{2}\left(y_{1}, y_{2}\right) .
$$

This is the $(\mathrm{CN})$ inequality of Bruhat and Tits [10]. In fact, a geodesic space is a CAT $(0)$ space if and only if it satisfies the (CN) inequality [7, p. 163].

In 2008, Dhompongsa and Panyanak [11] gave the following result, and the proof is similar to the proof of the remark in [12, p. 374].

Lemma 1.1 [11] Let X be a CAT(0) space. Then

$$
d((1-t) x \oplus t y, z) \leq(1-t) d(x, z)+t d(y, z)
$$

for all $x, y, z \in X$ and $t \in[0,1]$.

By the above lemma, we know that $\mathrm{CAT}(0)$ space is a convex metric space. Indeed, it is a metric space $X$ with a convex structure if there exists a mapping $W: X \times X \times[0,1] \rightarrow X$ such that

$$
d(W(x, y, t), z) \leq t d(x, z)+(1-t) d(y, z)
$$

for all $x, y, z \in X$ and $t \in[0,1]$ and this space $X$ is called a convex metric space [13]. Furthermore, Takahashi [13] has proved that

$$
d(x, y)=t d(x, W(x, y, t))+(1-t) d(y, W(x, y, t))
$$

for all $x, y, z \in X$ and $t \in[0,1]$ when $X$ is a convex metric space with a convex structure. So, we also get the following result, and it is proved in [11].

Lemma 1.2 [11] Let $X$ be a $C A T(0)$ space and $x, y \in X$. For each $t \in[0,1]$, there exists a unique point $z \in[x, y]$ such that $d(x, z)=t d(x, y)$ and $d(y, z)=(1-t) d(x, y)$.

For convenience, from now on we will use the notation $z=(1-t) x \oplus t y$. Therefore, we have

$$
\begin{aligned}
& z=(1-t) x \oplus t y \quad \Leftrightarrow \quad z \in[x, y], \\
& d(x, z)=t d(x, y), \quad \text { and } \quad d(y, z)=(1-t) d(x, y) .
\end{aligned}
$$

Let $C$ be a nonempty closed convex subset of a $\operatorname{CAT}(0)$ space $X$, and let $T$ be a nonexpansive mapping on $C$, i.e., $T: C \rightarrow C$ such that $d(T x, T y) \leq d(x, y)$ for all $x, y \in C$. We use $F(T)$ to denote the set of fixed points of $T$, i.e., $F(T):=\{x \in C: T x=x\}$. Let $\mathbb{N}$ be the set of 
positive integers, $\mathbb{R}$ be the set of real numbers, and let $\mathbb{R}_{+}$be the set of nonnegative real numbers.

A family $\{T(t): t \geq 0\}$ of mappings is called a one-parameter continuous semigroup of nonexpansive mappings on a nonempty closed convex subset $C$ of a CAT(0) space $X$ if the following conditions hold:

$(\mathrm{SG})_{1}$ for each $t \in \mathbb{R}_{+}, T(t)$ is a nonexpansive mapping on $C$;

$(\mathrm{SG})_{2} T(s+t)=T(t) \circ T(s)$ for all $t, s \in \mathbb{R}_{+}$;

$(\mathrm{SG})_{3}$ for each $x \in X$, the mapping $T(\cdot) x$ from $\mathbb{R}_{+}$into $C$ is continuous.

A family $\{T(t): t \geq 0\}$ of mappings is called a one-parameter strongly continuous semigroup of nonexpansive mappings on a nonempty closed convex subset $C$ of a $C A T(0)$ space $X$ if conditions $(\mathrm{SG})_{i}, i=1,2,3$, and the following condition are satisfied:

$(\mathrm{SG})_{4} T(0) x=x$ for all $x \in C$.

Note that if $C$ is a nonempty compact subset of a Banach space and $\{T(t): t \geq 0\}$ is a semigroup of nonexpansive mappings, then $\bigcap_{t \geq 0} F(T(t)) \neq \emptyset$ [14]; see also [15-17] and others. For the example of a one-parameter continuous semigroup of nonexpansive mappings, one can see [18].

Construction of common fixed points of a nonexpansive semigroup is an important subject in the theory of nonexpansive semigroup mappings and its applications. Fox example, one can refer to [19, 20]. In [21], Shioji and Takahashi introduced the implicit iteration

(A) $u_{n}=\alpha_{n} u+\left(1-\alpha_{n}\right) \frac{1}{t_{n}} \int_{0}^{t_{n}} T(s) u_{n} d s, n \geq 0$,

where $C$ is a nonempty closed convex subset of a real Hilbert space $H, u \in C,\left\{\alpha_{n}\right\}$ is a sequence in $(0,1),\left\{t_{n}\right\}$ is a sequence of positive real numbers divergent to $\infty$. Under suitable conditions, Shioji and Takahashi [21] proved strong convergence of $\left\{x_{n}\right\}$ to a member of $\bigcap_{t \geq 0} F(T(t))$. Note that their iterate $x_{n}$ at step $n$ is constructed through the average of a semigroup over the interval $(0, \infty)$.

In 2003, Suzuki [22] introduced the following implicit iteration process in a Hilbert space:

(B) $x_{n}=\alpha_{n} u+\left(1-\alpha_{n}\right) T\left(t_{n}\right) x_{n}, n \geq 0$

for a nonexpansive semigroup, where $C$ is a nonempty closed convex subset of a real Hilbert space $H, u \in C,\left\{\alpha_{n}\right\}$ is a sequence in $(0,1),\left\{t_{n}\right\}$ is a sequence of positive real numbers. Note that $x_{n}$ is constructed directly from the $T\left(t_{n}\right)$. So, Zegeye and Shahzad [23] viewed Suzuki's iteration process (B) as an extension of the implicit process (A) to nonexpansive semigroups.

In 2005, Suzuki [24] considered an iterative process $\left\{x_{n}\right\}$ for a one-parameter continuous semigroup of nonexpansive mappings on $C$, where $C$ is a nonempty compact convex subset of a Banach space $E$, defined by

$$
\left\{\begin{array}{l}
x_{1} \in C \quad \text { chosen arbitrary, } \\
x_{n+1}:=\lambda T\left(t_{n}\right) x_{n}+(1-\lambda) x_{n},
\end{array}\right.
$$

where $\lambda \in(0,1)$ and $\left\{t_{n}\right\} \subseteq[0, \infty)$. Then Suzuki [24] proved that $\left\{x_{n}\right\}$ converges strongly to a common fixed point of $\{T(t): t \geq 0\}$ if

$$
\liminf _{n \rightarrow \infty} t_{n}<\limsup _{n \rightarrow \infty} t_{n}, \quad \text { and } \quad \lim _{n \rightarrow \infty}\left(t_{n+1}-t_{n}\right)=0 .
$$


In 2009, Dhompongsa et al. [25] gave the following important result for a strongly continuous semigroup of nonexpansive mappings.

Theorem 1.1 [25] Let C be a nonempty bounded closed convex subset of a complete CAT(0) space $X$, and let $\{T(t): t \geq 0\}$ be a strongly continuous semigroup of nonexpansive mappings on C. Let $\left\{\alpha_{n}\right\}$ and $\left\{t_{n}\right\}$ be sequences of real numbers satisfying $0<\alpha_{n}<1, t_{n}>0$, and $\lim _{n \rightarrow \infty} t_{n}=\lim _{n \rightarrow \infty} \frac{\alpha_{n}}{t_{n}}=0$. Let $x_{0} \in C$, and let $\left\{x_{n}\right\}$ be a sequence in $C$ with

$$
x_{n}=\alpha_{n} x_{0} \oplus\left(1-\alpha_{n}\right) T\left(t_{n}\right) x_{n}, \quad \forall n \in \mathbb{N} .
$$

Then $\bigcap_{t \geq 0} F(T(t)) \neq \emptyset$ and $\left\{x_{n}\right\}$ converges to the element of $\bigcap_{t \geq 0} F(T(t))$ nearest to $x_{0}$.

In 2011, Cho et al. [26] gave the following result for a continuous semigroup of nonexpansive mappings on a nonempty compact convex subset $C$ of a complete $\operatorname{CAT}(0)$ space $X$.

Theorem 1.2 [26] Let C be a nonempty compact convex subset of a complete CAT(0) space $X$, and $\{T(t): t \geq 0\}$ be a one-parameter continuous semigroup of nonexpansive mappings on C. Let $\left\{t_{n}\right\}$ be a sequence in $[0, \infty)$ satisfying

$$
\liminf _{n \rightarrow \infty} t_{n}<\limsup _{n \rightarrow \infty} t_{n}, \quad \text { and } \quad \lim _{n \rightarrow \infty}\left(t_{n+1}-t_{n}\right)=0 .
$$

For any $\lambda \in(0,1)$, define a sequence $\left\{x_{n}\right\}$ in $C$ by

$$
\left\{\begin{array}{l}
x_{1} \in C \quad \text { chosen arbitrary, } \\
x_{n+1}:=\lambda T\left(t_{n}\right) x_{n} \oplus(1-\lambda) x_{n} .
\end{array}\right.
$$

Then $\left\{x_{n}\right\}$ converges to a common fixed point of the semigroup $\{T(t): t \geq 0\}$.

Remark 1.1 By Theorems 1.1 and 1.2, we know that

(a) if $C$ is a nonempty bounded closed convex subset of a complete CAT(0) space $X$, and $\{T(t): t \geq 0\}$ is a strongly continuous semigroup of nonexpansive mappings on $C$, then $\bigcap_{t \geq 0} F(T(t)) \neq \emptyset$;

(b) if $C$ is a compact convex subset of a complete $\operatorname{CAT}(0)$ space $X$, and $\{T(t): t \geq 0\}$ is a one-parameter continuous semigroup of nonexpansive mappings on $C$, then $\bigcap_{t \geq 0} F(T(t)) \neq \emptyset$.

Motivated by the above works and related results, we study the following iteration processes for some families of one-parameter continuous semigroups of nonexpansive mappings on a nonempty compact convex subset $C$ of a complete CAT(0) space $X$.

Let $\{T(t): t \geq 0\}$ and $\{Q(q): q \geq 0\}$ be one-parameter continuous semigroups of nonexpansive mappings on a nonempty compact convex subset $C$ of a complete CAT( 0$)$ space $X$. We consider the following iteration processes (1.3), (1.4), and (1.5):

$$
\left\{\begin{array}{l}
x_{1} \in C \quad \text { chosen arbitrary, } \\
y_{n}:=\left(1-\beta_{n}\right) x_{n} \oplus \beta_{n} T\left(t_{n}\right) x_{n}, \\
x_{n+1}:=\left(1-\alpha_{n}\right) x_{n} \oplus \alpha_{n} Q\left(q_{n}\right) y_{n},
\end{array}\right.
$$




$$
\left\{\begin{array}{l}
x_{1} \in C \quad \text { chosen arbitrary, } \\
y_{n}:=\left(1-\beta_{n}\right) x_{n} \oplus \beta_{n} T\left(t_{n}\right) x_{n}, \\
x_{n+1}:=\left(1-\alpha_{n}\right) y_{n} \oplus \alpha_{n} Q\left(q_{n}\right) y_{n},
\end{array}\right.
$$

where $\left\{\alpha_{n}\right\}$ and $\left\{\beta_{n}\right\}$ are sequences in $(0,1),\left\{t_{n}\right\}$ and $\left\{q_{n}\right\}$ are sequences in $[0, \infty)$. We prove that the proposed sequences converge to a common fixed point of these families of mappings. Note that our results generalize Theorem 1.1 (i.e., Theorem 3.5 in [26]).

Besides, Thong [27] considered an implicit iteration for nonexpansive semigroups $\{T(t): t \geq 0\}$ on a nonempty compact convex subset $C$ of a real Banach space $E$ as follows:

$$
\left\{\begin{array}{l}
x_{1} \in C \quad \text { chosen arbitrary, } \\
x_{n}:=\alpha_{n-1} x_{n}+\left(1-\alpha_{n}\right) T\left(t_{n}\right) x_{n}
\end{array}\right.
$$

where $\left\{\alpha_{n}\right\}$ is a sequence in $(0,1)$, and $\left\{t_{n}\right\}$ is a sequence in $[0, \infty)$.

In this paper, motivated by [27], we also consider the following implicit iteration process for some families of one-parameter continuous semigroups of nonexpansive mappings on a nonempty compact convex subset $C$ of a complete CAT(0) space $X$ :

$$
\left\{\begin{array}{l}
x_{1} \in C \quad \text { chosen arbitrary, } \\
y_{n}:=\left(1-\beta_{n}\right) x_{n} \oplus \beta_{n} T\left(t_{n}\right) x_{n}, \\
x_{n+1}:=\left(1-\alpha_{n+1}\right) Q\left(q_{n+1}\right) x_{n+1} \oplus \alpha_{n+1} y_{n}
\end{array}\right.
$$

where $\left\{\alpha_{n}\right\}$ and $\left\{\beta_{n}\right\}$ are sequences in $(0,1),\left\{t_{n}\right\}$ and $\left\{q_{n}\right\}$ are sequences in $[0, \infty)$.

For a special case of the iteration process (1.6), we have the following types:

$$
\begin{aligned}
& \left\{\begin{array}{l}
x_{1} \in C \quad \text { chosen arbitrary, } \\
x_{n+1}=\left(1-\alpha_{n+1}\right) Q\left(q_{n+1}\right) x_{n+1} \oplus \alpha_{n+1} x_{n}
\end{array}\right. \\
& \left\{\begin{array}{l}
x_{1} \in C \quad \text { chosen arbitrary, } \\
x_{n+1}:=\left(1-\beta_{n}\right) x_{n} \oplus \beta_{n} T\left(t_{n}\right) x_{n}
\end{array}\right.
\end{aligned}
$$

We prove the proposed sequences converge to a common fixed point of three families of mappings. Our result for the iteration process (1.7) is similar to (1.5) on complete CAT(0) spaces. Our results for the iteration processes (1.6) and (1.8) generalize Theorem 1.2. Note that the iteration process (1.8) is also a special case of the iteration processes (1.3) and (1.4).

\section{Preliminaries}

In 2005, Suzuki [24] gave the following result, and it is an important tool in this paper.

Lemma 2.1 [24] Let $\left\{t_{n}\right\}$ be a real sequence and $\tau$ be a real number satisfying $\liminf _{n \rightarrow \infty} t_{n} \leq \tau \leq \limsup _{n \rightarrow \infty} t_{n}$. Suppose that either of the following holds:

(i) $\lim \sup _{n \rightarrow \infty}\left(t_{n+1}-t_{n}\right) \leq 0$ or

(ii) $\liminf _{n \rightarrow \infty}\left(t_{n+1}-t_{n}\right) \geq 0$. 
Then $\tau$ is a cluster point of $\left\{t_{n}\right\}$. Moreover, for any $\varepsilon>0$ and $k, m \in \mathbb{N}$, there exists $m_{0} \geq m$ such that $\left|t_{j}-\tau\right|<\varepsilon$ for all $j \in \mathbb{N}$ with $m_{0} \leq j \leq m_{0}+k$.

Lemma 2.2 [11] Let $X$ be a $C A T(0)$ space. Then

$$
d((1-t) x \oplus t y, z)^{2} \leq(1-t) d(x, z)^{2}+t d(y, z)^{2}-t(1-t) d(x, y)^{2}
$$

for all $t \in[0,1]$ and $x, y, z \in X$.

Definition 2.1 Let $\left\{x_{n}\right\}$ be a bounded sequence in a $C A T(0)$ space $X$, and let $C$ be a subset of $X$. Now, we use the following notations:

(i) $r\left(x,\left\{x_{n}\right\}\right):=\limsup _{n \rightarrow \infty} d\left(x, x_{n}\right)$.

(ii) $r\left(\left\{x_{n}\right\}\right):=\inf _{x \in X} r\left(x,\left\{x_{n}\right\}\right)$.

(iii) $r_{C}\left(\left\{x_{n}\right\}\right):=\inf _{x \in C} r\left(x,\left\{x_{n}\right\}\right)$.

(iv) $A\left(\left\{x_{n}\right\}\right):=\left\{x \in X: r\left(x,\left\{x_{n}\right\}\right)=r\left(\left\{x_{n}\right\}\right)\right\}$.

(v) $A_{C}\left(\left\{x_{n}\right\}\right):=\left\{x \in C: r\left(x,\left\{x_{n}\right\}\right)=r_{C}\left(\left\{x_{n}\right\}\right)\right\}$.

Note that $x \in X$ is called an asymptotic center of $\left\{x_{n}\right\}$ if $x \in A\left(\left\{x_{n}\right\}\right)$. It is known that in a CAT $(0)$ space, $A\left(\left\{x_{n}\right\}\right)$ consists of exactly one point [28].

Definition 2.2 [6] Let $(X, d)$ be a $\operatorname{CAT}(0)$ space. A sequence $\left\{x_{n}\right\}$ in $X$ is said to be $\Delta$ convergent to $x \in X$ if $x$ is the unique asymptotic center of $\left\{u_{n}\right\}$ for every subsequence $\left\{u_{n}\right\}$ of $\left\{x_{n}\right\}$. That is, $A\left(\left\{u_{n}\right\}\right)=\{x\}$ for every subsequence $\left\{u_{n}\right\}$ of $\left\{x_{n}\right\}$. In this case, we write $\Delta-\lim _{n} x_{n}=x$ and call $x$ the $\Delta$-limit of $\left\{x_{n}\right\}$.

Lemma 2.3 [6] Let $(X, d)$ be a $C A T(0)$ space. Then every bounded sequence in $X$ has a $\Delta$-convergent subsequence.

Lemma 2.4 [29] Let $C$ be a nonempty closed convex subset of a CAT(0) space $X$. If $\left\{x_{n}\right\}$ is a bounded sequence in $C$, then the asymptotic center $A\left(\left\{x_{n}\right\}\right)$ of $\left\{x_{n}\right\}$ is in $C$.

Lemma 2.5 [6] Let $C$ be a nonempty closed convex subset of a complete $C A T(0)$ space $X$, and let $T: C \rightarrow C$ be a nonexpansive mapping. Let $\left\{x_{n}\right\}$ be a bounded sequence in $C$ with $\Delta-\lim _{n} x_{n}=x$ and $\lim _{n \rightarrow \infty} d\left(x_{n}, T x_{n}\right)=0$. Then $x \in C$ and $T x=x$.

Lemma 2.6 [30] Let $X$ be a CAT(0) space. Let $\left\{x_{n}\right\}$ and $\left\{y_{n}\right\}$ be two bounded sequences in $X$ with $\lim _{n \rightarrow \infty} d\left(x_{n}, y_{n}\right)=0$. If $\Delta-\lim _{n} x_{n}=x$, then $\Delta-\lim _{n} y_{n}=x$.

Next, we give the following results and these results show that the intersection of the fixed point sets for a continuous semigroup of nonexpansive mappings is nonempty. Note that Theorem 2.1 is different from Theorem 1.1.

\section{A: Common fixed point for a strongly nonexpansive semigroup}

Lemma 2.7 Let $C$ be a nonempty bounded closed convex subset of a complete CAT(0) space $X$. Let $\{T(t): t \in \mathbb{R}\}$ be a continuous semigroup of nonexpansive mappings on C. Let $\left\{t_{n}\right\}$ be a sequence in $\mathbb{R}_{+}$. Let $\left\{\alpha_{n}\right\}$ be a sequence in $(0,1)$, and let $\left\{x_{n}\right\}$ be defined as

$$
\left\{\begin{array}{l}
x_{0} \in C \quad \text { chosen arbitrary, } \\
x_{n}=\alpha_{n} x_{n-1} \oplus\left(1-\alpha_{n}\right) T\left(t_{n}\right) x_{n}, \quad n \geq 1 .
\end{array}\right.
$$


Assume that $\lim _{n \rightarrow \infty} t_{n}=\lim _{n \rightarrow \infty} \frac{\alpha_{n}}{t_{n}}=0$. Then $\bigcap_{t \geq 0} F(T(t)) \neq \emptyset$ if and only if $\lim _{n \rightarrow \infty} d\left(T(0) x_{n}, x_{n}\right)=0$.

Proof Suppose that $\lim _{n \rightarrow \infty} d\left(T(0) x_{n}, x_{n}\right)=0$. Since $C$ is bounded, there exist a subsequence $\left\{u_{n}\right\}$ of $\left\{x_{n}\right\}$ and $\bar{x} \in C$ such that $\Delta-\lim _{n \rightarrow \infty} u_{n}=\bar{x}$. By Lemma 2.5, $T(0) \bar{x}=\bar{x}$.

Take any $t>0$ and let $t$ be fixed. For $n>0$ with $\left[\frac{t}{t_{n}}\right]>1$, we have

$$
\begin{aligned}
& d\left(x_{n}, T(t) \bar{x}\right) \\
& \leq d\left(x_{n}, T(0) x_{n}\right)+\sum_{k=0}^{\left[\frac{t}{t_{n}}\right]-1} d\left(T\left((k+1) t_{n}\right) x_{n}, T\left(k t_{n}\right) x_{n}\right) \\
& \quad+d\left(T\left(\left[\frac{t}{t_{n}}\right] t_{n}\right) x_{n}, T\left(\left[\frac{t}{t_{n}}\right] t_{n}\right) \bar{x}\right)+d\left(T\left(\left[\frac{t}{t_{n}}\right] t_{n}\right) \bar{x}, T(t) \bar{x}\right) \\
& \leq d\left(x_{n}, T(0) x_{n}\right)+\left[\frac{t}{t_{n}}\right] d\left(T\left(t_{n}\right) x_{n}, x_{n}\right)+d\left(x_{n}, \bar{x}\right)+d\left(T\left(t-\left[\frac{t}{t_{n}}\right] t_{n}\right) \bar{x}, T(0) \bar{x}\right) \\
& \leq d\left(x_{n}, T(0) x_{n}\right)+\frac{t \alpha_{n}}{t_{n}} d\left(T\left(t_{n}\right) x_{n}, x_{n-1}\right)+d\left(x_{n}, \bar{x}\right) \\
& \quad+\max \left\{d(T(s) \bar{x}, T(0) \bar{x}): 0 \leq s \leq t_{n}\right\} \\
& \leq d\left(x_{n}, T(0) x_{n}\right)+\frac{t \alpha_{n}}{t_{n}} M+d\left(x_{n}, \bar{x}\right)+\max \left\{d(T(s) \bar{x}, T(0) \bar{x}): 0 \leq s \leq t_{n}\right\}
\end{aligned}
$$

for some $M>0$ (note that $C$ is bounded). Hence, we know that

$$
\limsup _{n \rightarrow \infty} d\left(u_{n}, T(t) \bar{x}\right) \leq \limsup _{n \rightarrow \infty} d\left(u_{n}, \bar{x}\right)
$$

for each $t>0$. Since $\Delta-\lim _{n \rightarrow \infty} u_{n}=\bar{x}, T(t) \bar{x}=\bar{x}$ for each $t>0$. Therefore, $\bar{x} \in \bigcap_{t \geq 0} F(T(t)) \neq \emptyset$.

Conversely, suppose that $\bigcap_{t \geq 0} F(T(t)) \neq \emptyset$. Now, take any $w \in \bigcap_{t \geq 0} F(T(t))$, and let $w$ be fixed. Then we have

$$
\begin{aligned}
& d\left(x_{n}, w\right)^{2} \\
& \quad \leq \alpha_{n} d\left(x_{n-1}, w\right)^{2}+\left(1-\alpha_{n}\right) d\left(T\left(t_{n}\right) x_{n}, w\right)^{2}-\alpha_{n}\left(1-\alpha_{n}\right) d\left(x_{n-1}, T\left(t_{n}\right) x_{n}\right) \\
& \quad \leq \alpha_{n} d\left(x_{n-1}, w\right)^{2}+\left(1-\alpha_{n}\right) d\left(x_{n}, w\right)^{2}-\alpha_{n}\left(1-\alpha_{n}\right) d\left(x_{n-1}, T\left(t_{n}\right) x_{n}\right) \\
& \quad \leq \alpha_{n} d\left(x_{n-1}, w\right)^{2}+\left(1-\alpha_{n}\right) d\left(x_{n}, w\right)^{2} .
\end{aligned}
$$

And this implies that $d\left(x_{n}, w\right) \leq d\left(x_{n-1}, w\right)$ and $\lim _{n \rightarrow \infty} d\left(x_{n}, w\right)$ exists. Hence,

$$
d\left(x_{n-1}, T\left(t_{n}\right) x_{n}\right) \leq d\left(x_{n-1}, w\right)^{2}-d\left(x_{n}, w\right)^{2}+\alpha_{n} d\left(x_{n-1}, T\left(t_{n}\right) x_{n}\right) .
$$

By assumption, $\lim _{n \rightarrow \infty} d\left(x_{n-1}, T\left(t_{n}\right) x_{n}\right)=0$. Next, we get

$$
d\left(x_{n}, x_{n-1}\right)=d\left(\alpha_{n} x_{n-1} \oplus\left(1-\alpha_{n}\right) T\left(t_{n}\right) x_{n}, x_{n-1}\right)=\left(1-\alpha_{n}\right) d\left(T\left(t_{n}\right) x_{n}, x_{n-1}\right) .
$$


This implies that $\lim _{n \rightarrow \infty} d\left(x_{n}, x_{n+1}\right)=0$ and $\lim _{n \rightarrow \infty} d\left(x_{n}, T\left(t_{n}\right) x_{n}\right)=0$. Furthermore, it follows that

$$
\begin{aligned}
& \limsup _{n \rightarrow \infty} d\left(T(0) x_{n}, x_{n}\right) \\
& \quad \leq \limsup _{n \rightarrow \infty}\left(d\left(T(0) x_{n}, T\left(0+t_{n}\right) x_{n}\right)+d\left(T\left(t_{n}\right) x_{n}, x_{n}\right)\right) \\
& \quad \leq \limsup _{n \rightarrow \infty}\left(d\left(T(0) x_{n}, T(0) \circ T\left(t_{n}\right) x_{n}\right)+d\left(T\left(t_{n}\right) x_{n}, x_{n}\right)\right) \\
& \quad \leq \limsup _{n \rightarrow \infty} 2 d\left(x_{n}, T\left(t_{n}\right) x_{n}\right)=0 .
\end{aligned}
$$

Therefore, the proof is completed.

By Lemma 2.7, we get the following theorem, and it is different from Theorem 1.1.

Theorem 2.1 Let $C$ be a nonempty bounded closed convex subset of a complete CAT(0) space $X$. Let $\{T(t): t \in \mathbb{R}\}$ be a strongly continuous semigroup of nonexpansive mappings on C. Let $\left\{t_{n}\right\}$ be a sequence in $\mathbb{R}_{+}$, and $\left\{\alpha_{n}\right\}$ be a sequence in $(0,1)$ with $\lim _{n \rightarrow \infty} t_{n}=$ $\lim _{n \rightarrow \infty} \frac{\alpha_{n}}{t_{n}}=0$. Let $\left\{x_{n}\right\}$ be defined as

$$
\left\{\begin{array}{l}
x_{0} \in C \quad \text { chosen arbitrary, } \\
x_{n}=\alpha_{n} x_{n-1} \oplus\left(1-\alpha_{n}\right) T\left(t_{n}\right) x_{n}, \quad n \geq 1 .
\end{array}\right.
$$

Then $\bigcap_{t \geq 0} F(T(t)) \neq \emptyset$. Furthermore, if $C$ is a compact set, then $\lim _{n \rightarrow \infty} d\left(x_{n}, \bar{x}\right)=0$ for some $\bar{x} \in \Omega$.

Proof Since $\{T(t): t \in \mathbb{R}\}$ is a strongly continuous semigroup of nonexpansive mappings on $C$, it is easy to see that $\lim _{n \rightarrow \infty} d\left(T(0) x_{n}, x_{n}\right)=0$. By Lemma $2.7, \bigcap_{t \geq 0} F(T(t)) \neq \emptyset$, and the proof is completed.

\section{B: Common fixed point for a nonexpansive semigroup}

Lemma 2.8 Let $C$ be a nonempty bounded closed convex subset of a complete CAT $(0)$ space $X$, and $\{T(t): t \geq 0\}$ be a one-parameter continuous semigroup of nonexpansive mappings on C. Let $\left\{t_{n}\right\}$ be a sequence in $[0, \infty)$ satisfying

$$
\liminf _{n \rightarrow \infty} t_{n}<\limsup _{n \rightarrow \infty} t_{n}, \quad \text { and } \quad \lim _{n \rightarrow \infty}\left(t_{n+1}-t_{n}\right)=0 .
$$

For any $\lambda \in(0,1)$, define a sequence $\left\{x_{n}\right\}$ in $C$ by

$$
\left\{\begin{array}{l}
x_{1} \in C \quad \text { chosen arbitrary, } \\
x_{n+1}:=\lambda T\left(t_{n}\right) x_{n} \oplus(1-\lambda) x_{n} .
\end{array}\right.
$$

Then $\bigcap_{t \geq 0} F(T(t)) \neq \emptyset$ if and only if $\lim _{n \rightarrow \infty} d\left(x_{n}, T(0) x_{n}\right)=0$.

Proof Suppose that $\lim _{n \rightarrow \infty} d\left(x_{n}, T(0) x_{n}\right)=0$. Following the same argument as in the proof of Theorem 4 in [24], we get $\bigcap_{t \geq 0} F(T(t)) \neq \emptyset$. Conversely, if $\bigcap_{t \geq 0} F(T(t)) \neq \emptyset$, it is easy to see that $\lim _{n \rightarrow \infty} d\left(x_{n}, T(0) x_{n}\right)=0$. 
By Lemma 2.8, we get the following theorem. Notice also that it is a consequence of Theorem 1.2.

Theorem 2.2 Let $C$ be a nonempty compact convex subset of a complete CAT(0) space $X$, and $\{T(t): t \geq 0\}$ be a one-parameter continuous semigroup of nonexpansive mappings on C. Let $\left\{t_{n}\right\}$ be a sequence in $[0, \infty)$ satisfying

$$
\liminf _{n \rightarrow \infty} t_{n}<\limsup _{n \rightarrow \infty} t_{n}, \quad \text { and } \quad \lim _{n \rightarrow \infty}\left(t_{n+1}-t_{n}\right)=0 .
$$

For any $\lambda \in(0,1)$, define a sequence $\left\{x_{n}\right\}$ in $C$ by

$$
\left\{\begin{array}{l}
x_{1} \in C \quad \text { chosen arbitrary, } \\
x_{n+1}:=\lambda T\left(t_{n}\right) x_{n} \oplus(1-\lambda) x_{n} .
\end{array}\right.
$$

Then $\bigcap_{t \geq 0} F(T(t)) \neq \emptyset$.

Proof Following the same argument as in the proof of Theorem 3.5 in [26], we can prove that $\lim _{n \rightarrow \infty} d\left(x_{n}, T(0) x_{n}\right)=0$. By Lemma $2.8, \bigcap_{t \geq 0} F(T(t)) \neq \emptyset$.

\section{Main results}

Theorem 3.1 Let $C$ be a nonempty compact convex subset of a complete $C A T(0)$ space $X$. Let $\left\{T(t): t \in \mathbb{R}_{+}\right\}$and $\left\{Q(q): q \in \mathbb{R}_{+}\right\}$be continuous semigroups of nonexpansive mappings on C. Let $\left\{t_{n}\right\}$ and $\left\{q_{n}\right\}$ be sequences in $\mathbb{R}_{+}$. Let $\left\{\alpha_{n}\right\}$ and $\left\{\beta_{n}\right\}$ be sequences in $[0,1]$. Suppose that

$$
\Omega:=\left(\bigcap_{t \geq 0} F(T(t))\right) \cap\left(\bigcap_{q \geq 0} F(Q(q))\right) \neq \emptyset .
$$

Let $\left\{x_{n}\right\}$ be defined as

$$
\left\{\begin{array}{l}
x_{1} \in C \quad \text { chosen arbitrary, } \\
y_{n}:=\left(1-\beta_{n}\right) x_{n} \oplus \beta_{n} T\left(t_{n}\right) x_{n}, \\
x_{n+1}:=\left(1-\alpha_{n}\right) x_{n} \oplus \alpha_{n} Q\left(q_{n}\right) y_{n} .
\end{array}\right.
$$

Assume that

(i) $0<a \leq \alpha_{n} \leq b<1, \liminf _{n \rightarrow \infty} \beta_{n}\left(1-\beta_{n}\right)>0$;

(ii) $\max \left\{\liminf _{n \rightarrow \infty} t_{n}, \liminf _{n \rightarrow \infty} q_{n}\right\}<\min \left\{\limsup _{n \rightarrow \infty} t_{n}, \limsup _{n \rightarrow \infty} q_{n}\right\}$;

(iii) either $\limsup _{n \rightarrow \infty}\left(t_{n+1}-t_{n}\right) \leq 0$ or $\liminf _{n \rightarrow \infty}\left(t_{n+1}-t_{n}\right) \geq 0$ holds;

(iv) either $\lim _{\sup _{n \rightarrow \infty}}\left(q_{n+1}-q_{n}\right) \leq 0$ or $\liminf _{n \rightarrow \infty}\left(q_{n+1}-q_{n}\right) \geq 0$ holds.

Then $\lim _{n \rightarrow \infty} x_{n}=\bar{x}$ for some $\bar{x} \in \Omega$.

Proof Take any $w \in \Omega$, and let $w$ be fixed. Then for each $n \in \mathbb{N}$,

$$
\begin{aligned}
& d\left(y_{n}, w\right)^{2} \\
& \quad=d\left(\left(1-\beta_{n}\right) x_{n} \oplus \beta_{n} T\left(t_{n}\right) x_{n}, w\right)^{2}
\end{aligned}
$$




$$
\begin{aligned}
& \leq\left(1-\beta_{n}\right) d\left(x_{n}, w\right)^{2}+\beta_{n} d\left(T\left(t_{n}\right) x_{n}, w\right)^{2}-\beta_{n}\left(1-\beta_{n}\right) d\left(x_{n}, T\left(t_{n}\right) x_{n}\right)^{2} \\
& \leq\left(1-\beta_{n}\right) d\left(x_{n}, w\right)^{2}+\beta_{n} d\left(x_{n}, w\right)^{2}-\beta_{n}\left(1-\beta_{n}\right) d\left(x_{n}, T\left(t_{n}\right) x_{n}\right)^{2} \\
& \leq d\left(x_{n}, w\right)^{2}
\end{aligned}
$$

and

$$
\begin{aligned}
d( & \left.x_{n+1}, w\right)^{2} \\
& =d\left(\left(1-\alpha_{n}\right) x_{n} \oplus \alpha_{n} Q\left(q_{n}\right) y_{n}, w\right)^{2} \\
& \leq\left(1-\alpha_{n}\right) d\left(x_{n}, w\right)^{2}+\alpha_{n} d\left(Q\left(q_{n}\right) y_{n}, w\right)^{2}-\alpha_{n}\left(1-\alpha_{n}\right) d\left(x_{n}, Q\left(q_{n}\right) y_{n}\right)^{2} \\
& \leq\left(1-\alpha_{n}\right) d\left(x_{n}, w\right)^{2}+\alpha_{n} d\left(Q\left(q_{n}\right) y_{n}, w\right)^{2} \\
& \leq\left(1-\alpha_{n}\right) d\left(x_{n}, w\right)^{2}+\alpha_{n} d\left(y_{n}, w\right)^{2} \\
& \leq d\left(x_{n}, w\right)^{2} .
\end{aligned}
$$

Hence, $\lim _{n \rightarrow \infty} d\left(x_{n}, w\right)$ exists, and $\left\{x_{n}\right\}$ and $\left\{y_{n}\right\}$ are bounded sequences. By (3.2), we get

$$
\begin{aligned}
& d\left(x_{n}, w\right)^{2}+\frac{d\left(x_{n+1}, w\right)^{2}-d\left(x_{n}, w\right)^{2}}{a} \\
& \quad \leq d\left(x_{n}, w\right)^{2}+\frac{d\left(x_{n+1}, w\right)^{2}-d\left(x_{n}, w\right)^{2}}{\alpha_{n}} \\
& \quad=\frac{d\left(x_{n+1}, w\right)^{2}-\left(1-\alpha_{n}\right) d\left(x_{n}, w\right)^{2}}{\alpha_{n}} \\
& \quad \leq d\left(Q\left(q_{n}\right) y_{n}, w\right)^{2} \\
& \quad \leq d\left(y_{n}, w\right)^{2} \\
& \leq d\left(x_{n}, w\right)^{2} .
\end{aligned}
$$

And this implies that

$$
\lim _{n \rightarrow \infty} d\left(x_{n}, w\right)=\lim _{n \rightarrow \infty} d\left(y_{n}, w\right)=\lim _{n \rightarrow \infty} d\left(Q\left(q_{n}\right) y_{n}, w\right)
$$

By (3.1) and (3.4), we have

$$
\lim _{n \rightarrow \infty} \beta_{n}\left(1-\beta_{n}\right) d\left(x_{n}, T\left(t_{n}\right) x_{n}\right)^{2}=0 .
$$

By assumption and (3.5),

$$
\lim _{n \rightarrow \infty} d\left(x_{n}, T\left(t_{n}\right) x_{n}\right)=0 .
$$

By (3.2), we also have

$$
\alpha_{n}\left(1-\alpha_{n}\right) d\left(x_{n}, Q\left(q_{n}\right) y_{n}\right)^{2} \leq d\left(x_{n}, w\right)^{2}-d\left(x_{n+1}, w\right)^{2}
$$

and this inequality and assumption imply that

$$
\lim _{n \rightarrow \infty} d\left(x_{n}, Q\left(q_{n}\right) y_{n}\right)=0
$$


By (3.6), we have

$$
\begin{aligned}
\limsup _{n \rightarrow \infty} d\left(x_{n}, y_{n}\right) & =\limsup _{n \rightarrow \infty} d\left(\left(1-\beta_{n}\right) x_{n} \oplus \beta_{n} T\left(t_{n}\right) x_{n}, x_{n}\right) \\
& \leq \limsup _{n \rightarrow \infty} d\left(x_{n}, T\left(t_{n}\right) x_{n}\right)=0 .
\end{aligned}
$$

By (3.7), it is easy to see that

$$
\lim _{n \rightarrow \infty} d\left(x_{n+1}, x_{n}\right)=0 .
$$

By (3.7), (3.8), and (3.9), it is easy to see that

$$
\lim _{n \rightarrow \infty} d\left(y_{n}, Q\left(q_{n}\right) y_{n}\right)=\lim _{n \rightarrow \infty} d\left(x_{n+1}, Q\left(q_{n}\right) y_{n}\right)=0 .
$$

Furthermore, by (3.6), it follows that

$$
\begin{aligned}
& \limsup _{n \rightarrow \infty} d\left(T(0) x_{n}, x_{n}\right) \\
& \quad \leq \limsup _{n \rightarrow \infty}\left(d\left(T(0) x_{n}, T\left(0+t_{n}\right) x_{n}\right)+d\left(T\left(t_{n}\right) x_{n}, x_{n}\right)\right) \\
& \quad \leq \limsup _{n \rightarrow \infty}\left(d\left(T(0) x_{n}, T(0) \circ T\left(t_{n}\right) x_{n}\right)+d\left(T\left(t_{n}\right) x_{n}, x_{n}\right)\right) \\
& \quad \leq \limsup _{n \rightarrow \infty} 2 d\left(x_{n}, T\left(t_{n}\right) x_{n}\right)=0 .
\end{aligned}
$$

By (3.10), it follows that

$$
\limsup _{n \rightarrow \infty} d\left(Q(0) y_{n}, y_{n}\right)=0 .
$$

Next, fix $\tau, \delta \in \mathbb{R}$ with

$$
\max \left\{\liminf _{n \rightarrow \infty} t_{n}, \liminf _{n \rightarrow \infty} q_{n}\right\}<\tau<\tau+\delta<\min \left\{\limsup _{n \rightarrow \infty} t_{n}, \limsup _{n \rightarrow \infty} q_{n}\right\} .
$$

Following the same argument as in the proof of Theorem 4 in [24], we choose a subsequence $\left\{n_{i}\right\}$ of $\{n\}$ such that

$$
\begin{aligned}
& \lim _{n \rightarrow \infty} \frac{d\left(T\left(t_{n_{i}}\right) x_{n_{i}}, x_{n_{i}}\right)}{t_{n_{i}}-\tau}=\lim _{n \rightarrow \infty} \frac{d\left(Q\left(q_{n_{i}}\right) y_{n_{i}}, y_{n_{i}}\right)}{q_{n_{i}}-\tau}=0, \\
& \lim _{i \rightarrow \infty} t_{n_{i}}=\lim _{i \rightarrow \infty} q_{n_{i}}=\tau .
\end{aligned}
$$

For completeness, we give the following proof. By (3.6) and (3.10), there exists $m_{1} \in \mathbb{N}$ such that

$$
d\left(x_{n}, T\left(t_{n}\right) x_{n}\right)<\frac{1}{3^{2}}, \quad \text { and } \quad d\left(y_{n}, Q\left(q_{n}\right) y_{n}\right)<\frac{1}{3^{2}}
$$

for all $n \geq m_{1}$. By Lemma 2.1, we note that $\tau+\frac{\delta}{2}$ is a cluster point of $\left\{t_{n}\right\}$ and $\left\{q_{n}\right\}$. Hence, there exists $n_{1}>m_{1}$ such that

$$
\tau+\frac{\delta}{3}<t_{n_{1}}, q_{n_{1}}<\tau+\delta
$$


By (3.6) and (3.10) again, there exists $m_{2}>n_{1}$ such that

$$
d\left(x_{n}, T\left(t_{n}\right) x_{n}\right)<\frac{1}{4^{2}}, \quad \text { and } \quad d\left(y_{n}, Q\left(q_{n}\right) y_{n}\right)<\frac{1}{4^{2}}
$$

for all $n \geq m_{2}$. By Lemma 2.1 again, we note that $\tau+\frac{\delta}{3}$ is a cluster point of $\left\{t_{n}\right\}$ and $\left\{q_{n}\right\}$. Hence, there exists $n_{2}>m_{2}$ such that

$$
\tau+\frac{\delta}{4}<t_{n_{2}}, q_{n_{2}}<\tau+\frac{\delta}{2}
$$

Continuing this argument, we can define a subsequence $\left\{n_{i}\right\}$ of $\{n\}$ satisfying

$$
\begin{aligned}
& \max \left\{d\left(x_{n_{i}}, T\left(t_{n_{i}}\right) x_{n_{i}}\right), d\left(y_{n_{i}}, Q\left(q_{n_{i}}\right) y_{n_{i}}\right)\right\}<\frac{1}{(i+2)^{2}}, \quad \text { and } \\
& \tau+\frac{\delta}{i+2}<t_{n_{i}}, q_{n_{i}}<\tau+\frac{\delta}{i}
\end{aligned}
$$

for all $i \in \mathbb{N}$. Then it is obvious that $\tau<\min \left\{t_{n_{i}}, q_{n_{i}}\right\}$ for all $i \in \mathbb{N}$,

$$
\lim _{i \rightarrow \infty} t_{n_{i}}=\lim _{i \rightarrow \infty} q_{n_{i}}=\tau,
$$

and

$$
\lim _{i \rightarrow \infty} d\left(T\left(t_{n_{i}}\right) x_{n_{i}}, x_{n_{i}}\right)=\lim _{i \rightarrow \infty} d\left(Q\left(q_{n_{i}}\right) y_{n_{i}}, y_{n_{i}}\right)=0
$$

We also have

$$
\begin{aligned}
0 & \leq \limsup _{i \rightarrow \infty} \frac{d\left(T\left(t_{n_{i}}\right) x_{n_{i}}, x_{n_{i}}\right)}{t_{n_{i}}-\tau} \leq \limsup _{i \rightarrow \infty} \frac{1 /(i+2)^{2}}{\delta /(i+2)} \\
& =\limsup _{i \rightarrow \infty} \frac{1}{\delta(i+2)}=0 .
\end{aligned}
$$

Similarly,

$$
\lim _{i \rightarrow \infty} \frac{d\left(Q\left(q_{n_{i}}\right) y_{n_{i}}, y_{n_{i}}\right)}{q_{n_{i}}-\tau}=0 .
$$

Since $\left\{x_{n}\right\}$ is a bounded sequence, there exist a subsequence $\left\{x_{n_{i_{k}}}\right\}$ of $\left\{x_{n_{i}}\right\}$ and $\bar{x} \in C$ such that $\Delta-\lim _{k \rightarrow \infty} x_{n_{i_{k}}}=\bar{x}$. Let $u_{k}=x_{n_{i_{k}}}, v_{k}=y_{n_{i_{k}}}, a_{k}=t_{n_{i_{k}}}$, and $b_{k}=s_{n_{i_{k}}}$. Then we get

$$
\begin{aligned}
& \limsup _{k \rightarrow \infty} d\left(u_{k}, T(\tau) \bar{x}\right) \\
& \quad \leq \limsup _{k \rightarrow \infty}\left(d\left(u_{k}, T\left(a_{k}\right) u_{k}\right)+d\left(T\left(a_{k}\right) u_{k}, T\left(a_{k}\right) \bar{x}\right)+d\left(T\left(a_{k}\right) \bar{x}, T(\tau) \bar{x}\right)\right) \\
& \quad \leq \limsup _{k \rightarrow \infty} d\left(u_{k}, T\left(a_{k}\right) u_{k}\right)+\limsup _{k \rightarrow \infty} d\left(u_{k}, \bar{x}\right)+\limsup _{k \rightarrow \infty} d\left(T\left(a_{k}-\tau\right) \bar{x}, T(0) \bar{x}\right) \\
& \quad \leq \limsup _{k \rightarrow \infty} d\left(u_{k}, \bar{x}\right),
\end{aligned}
$$


and

$$
\begin{aligned}
& \limsup _{k \rightarrow \infty} d\left(v_{k}, Q(\tau) \bar{x}\right) \\
& \quad \leq \limsup _{k \rightarrow \infty}\left(d\left(v_{k}, Q\left(b_{k}\right) v_{k}\right)+d\left(Q\left(b_{k}\right) v_{k}, Q\left(b_{k}\right) \bar{x}\right)+d\left(Q\left(b_{k}\right) \bar{x}, Q(\tau) \bar{x}\right)\right) \\
& \quad \leq \limsup _{k \rightarrow \infty} d\left(v_{k}, Q\left(b_{k}\right) v_{k}\right)+\limsup _{k \rightarrow \infty} d\left(v_{k}, \bar{x}\right)+\limsup _{k \rightarrow \infty} d\left(Q\left(b_{k}-\tau\right) \bar{x}, Q(0) \bar{x}\right) \\
& \quad \leq \limsup _{k \rightarrow \infty} d\left(v_{k}, \bar{x}\right) .
\end{aligned}
$$

Since $\Delta-\lim _{k \rightarrow \infty} u_{k}=\bar{x}$, we know that $T(\tau) \bar{x}=\bar{x}$. By (3.8), $\Delta-\lim _{k \rightarrow \infty} u_{k}=\bar{x}$, and Lemma 2.6, we know that $\Delta-\lim _{k \rightarrow \infty} v_{k}=\bar{x}$, and this implies that $Q(\tau) \bar{x}=\bar{x}$. Also, we have

$$
T(0) \bar{x}=T(0) \circ T(\tau) \bar{x}=T(\tau+0) \bar{x}=T(\tau) \bar{x}=\bar{x} .
$$

Similarly, $Q(0) \bar{x}=\bar{x}$.

Take any $t>0$, and let $t$ be fixed. Then for $k \in \mathbb{N}$ with $a_{k}-\tau<t$, we have

$$
\begin{aligned}
d\left(u_{k}, T(t) \bar{x}\right) & \\
= & d\left(u_{k}, T(t) \circ T(\tau)^{\left[t /\left(a_{k}-\tau\right)\right]} \bar{x}\right) \\
= & d\left(u_{k}, T\left(\left[t /\left(a_{k}-\tau\right)\right] \tau+t\right) \bar{x}\right) \\
\leq & d\left(u_{k}, T(0) u_{k}\right)+\sum_{m=0}^{\left[t /\left(a_{k}-\tau\right)\right]-1} d\left(T\left((m+1) a_{k}\right) u_{k}, T\left(m a_{k}\right) u_{k}\right) \\
& +d\left(T\left(\left[t /\left(a_{k}-\tau\right)\right] a_{k}\right) u_{k}, T\left(\left[t /\left(a_{k}-\tau\right)\right] a_{k}\right) \bar{x}\right) \\
& +d\left(T\left(\left[t /\left(a_{k}-\tau\right)\right] a_{k}\right) \bar{x}, T\left(\left[t /\left(a_{k}-\tau\right)\right] \tau+t\right) \bar{x}\right) \\
\leq & d\left(u_{k}, T(0) u_{k}\right)+\left[t /\left(a_{k}-\tau\right)\right] \cdot d\left(T\left(a_{k}\right) u_{k}, u_{k}\right)+d\left(u_{k}, \bar{x}\right) \\
& +d\left(T\left(t-\left[t /\left(a_{k}-\tau\right)\right]\left(a_{k}-\tau\right)\right) \bar{x}, T(0) \bar{x}\right) \\
\leq & d\left(u_{k}, T(0) u_{k}\right)+\frac{t \cdot d\left(T\left(a_{k}\right) u_{k}, u_{k}\right)}{a_{k}-\tau}+d\left(u_{k}, \bar{x}\right) \\
& +\max \left\{d(T(s) \bar{x}, T(0) \bar{x}): 0 \leq s \leq a_{k}-\tau\right\} .
\end{aligned}
$$

By (3.11) and (3.13), we get

$$
\limsup _{k \rightarrow \infty} d\left(u_{k}, T(t) \bar{x}\right) \leq \limsup _{k \rightarrow \infty} d\left(u_{k}, \bar{x}\right)
$$

Since $\Delta-\lim _{k \rightarrow \infty} u_{k}=\bar{x}$, we get $T(t) \bar{x}=\bar{x}$ for each $t \geq 0$. Therefore, $\bar{x}$ is a common fixed point of $\{T(t): t \geq 0\}$. Furthermore, we know that $\bar{x} \in \Omega$ by following the same argument. In fact, since $C$ is a compact set, we may assume that $\lim _{k \rightarrow \infty} d\left(x_{n_{i_{k}}}, \bar{x}\right)=0$. So, $\bar{x}$ is a cluster point of $\left\{x_{n}\right\}$ and $\liminf _{n \rightarrow \infty} d\left(x_{n}, \bar{x}\right)=0$. Since $\lim _{n \rightarrow \infty} d\left(x_{n}, w\right)$ exists for each $w \in$ $\Omega, \lim _{n \rightarrow \infty} d\left(x_{n}, \bar{x}\right)=0$. Therefore, the proof is completed.

Remark 3.1 Theorem 3.1 generalizes Theorem 1.2. 
Theorem 3.2 Let $C$ be a nonempty compact convex subset of a complete CAT(0) space X. Let $\left\{T(t): t \in \mathbb{R}_{+}\right\}$and $\left\{Q(q): q \in \mathbb{R}_{+}\right\}$be continuous semigroups of nonexpansive mappings on C. Let $\left\{t_{n}\right\}$ and $\left\{q_{n}\right\}$ be sequences in $\mathbb{R}_{+}$. Let $\left\{\alpha_{n}\right\}$ and $\left\{\beta_{n}\right\}$ be sequences in $[0,1]$. Suppose that

$$
\Omega:=\left(\bigcap_{t \geq 0} F(T(t))\right) \cap\left(\bigcap_{q \geq 0} F(Q(q))\right) \neq \emptyset .
$$

Let $\left\{x_{n}\right\}$ be defined as

$$
\left\{\begin{array}{l}
x_{1} \in C \quad \text { chosen arbitrary, } \\
y_{n}:=\left(1-\beta_{n}\right) x_{n} \oplus \beta_{n} T\left(t_{n}\right) x_{n}, \\
x_{n+1}:=\left(1-\alpha_{n}\right) y_{n} \oplus \alpha_{n} Q\left(q_{n}\right) y_{n} .
\end{array}\right.
$$

Assume that

(i) $\liminf _{n \rightarrow \infty} \alpha_{n}\left(1-\alpha_{n}\right)>0, \liminf _{n \rightarrow \infty} \beta_{n}\left(1-\beta_{n}\right)>0$;

(ii) $\max \left\{\liminf _{n \rightarrow \infty} t_{n}, \liminf _{n \rightarrow \infty} q_{n}\right\}<\min \left\{\limsup _{n \rightarrow \infty} t_{n}, \limsup _{n \rightarrow \infty} q_{n}\right\}$;

(iii) either $\lim \sup _{n \rightarrow \infty}\left(t_{n+1}-t_{n}\right) \leq 0$ or $\liminf _{n \rightarrow \infty}\left(t_{n+1}-t_{n}\right) \geq 0$ holds;

(iv) either $\lim \sup _{n \rightarrow \infty}\left(q_{n+1}-q_{n}\right) \leq 0$ or $\liminf _{n \rightarrow \infty}\left(q_{n+1}-q_{n}\right) \geq 0$ holds.

Then $\lim _{n \rightarrow \infty} x_{n}=\bar{x}$ for some $\bar{x} \in \Omega$.

Proof Take any $w \in \Omega$, and let $w$ be fixed. Then for each $n \in \mathbb{N}$,

$$
\begin{aligned}
& d\left(y_{n}, w\right)^{2} \\
& \quad=d\left(\left(1-\beta_{n}\right) x_{n} \oplus \beta_{n} T\left(t_{n}\right) x_{n}, w\right)^{2} \\
& \quad=\left(1-\beta_{n}\right) d\left(x_{n}, w\right)^{2}+\beta_{n} d\left(T\left(t_{n}\right) x_{n}, w\right)^{2}-\beta_{n}\left(1-\beta_{n}\right) d\left(x_{n}, T\left(t_{n}\right) x_{n}\right)^{2} \\
& \quad \leq\left(1-\beta_{n}\right) d\left(x_{n}, w\right)^{2}+\beta_{n} d\left(x_{n}, w\right)^{2}-\beta_{n}\left(1-\beta_{n}\right) d\left(x_{n}, T\left(t_{n}\right) x_{n}\right)^{2} \\
& \quad \leq d\left(x_{n}, w\right)^{2}
\end{aligned}
$$

and

$$
\begin{aligned}
& d\left(x_{n+1}, w\right)^{2} \\
& \quad=d\left(\left(1-\alpha_{n}\right) y_{n} \oplus \alpha_{n} Q\left(q_{n}\right) y_{n}, w\right)^{2} \\
& \quad=\left(1-\alpha_{n}\right) d\left(y_{n}, w\right)^{2}+\alpha_{n} d\left(Q\left(q_{n}\right) y_{n}, w\right)^{2}-\alpha_{n}\left(1-\alpha_{n}\right) d\left(y_{n}, Q\left(q_{n}\right) y_{n}\right)^{2} \\
& \quad \leq d\left(y_{n}, w\right)^{2}-\alpha_{n}\left(1-\alpha_{n}\right) d\left(y_{n}, Q\left(q_{n}\right) y_{n}\right)^{2} \\
& \quad \leq d\left(x_{n}, w\right)^{2}-\alpha_{n}\left(1-\alpha_{n}\right) d\left(y_{n}, Q\left(q_{n}\right) y_{n}\right)^{2} .
\end{aligned}
$$

Hence, $\lim _{n \rightarrow \infty} d\left(x_{n}, w\right)$ exists, $\lim _{n \rightarrow \infty} d\left(x_{n}, w\right)=\lim _{n \rightarrow \infty} d\left(y_{n}, w\right)$, and $\left\{x_{n}\right\}$ and $\left\{y_{n}\right\}$ are bounded sequences. By (3.14) and $\lim _{n \rightarrow \infty} d\left(x_{n}, w\right)=\lim _{n \rightarrow \infty} d\left(y_{n}, w\right)$, we have

$$
\lim _{n \rightarrow \infty} \beta_{n}\left(1-\beta_{n}\right) d\left(x_{n}, T\left(t_{n}\right) x_{n}\right)^{2}=0 .
$$

By assumption and (3.16),

$$
\lim _{n \rightarrow \infty} d\left(x_{n}, T\left(t_{n}\right) x_{n}\right)=0 .
$$


By (3.15) and $\lim _{n \rightarrow \infty} d\left(x_{n}, w\right)$ exists,

$$
\lim _{n \rightarrow \infty} d\left(y_{n}, Q\left(q_{n}\right) y_{n}\right)=0
$$

By (3.17), we have

$$
\begin{aligned}
\limsup _{n \rightarrow \infty} d\left(x_{n}, y_{n}\right) & =\limsup _{n \rightarrow \infty} d\left(x_{n},\left(1-\beta_{n}\right) x_{n} \oplus \beta_{n} T\left(t_{n}\right) x_{n}\right) \\
& \leq \limsup _{n \rightarrow \infty} d\left(x_{n}, T\left(t_{n}\right) x_{n}\right)=0
\end{aligned}
$$

Next, following the same argument as in the proof of Theorem 3.1, we get the proof of Theorem 3.2.

Remark 3.2 Theorem 1.2 is also a special case of Theorem 3.2.

Theorem 3.3 Let $C$ be a nonempty compact convex subset of a complete $C A T(0)$ space $X$. Let $\{T(t): t \in \mathbb{R}\}$ and $\{Q(q): q \in \mathbb{R}\}$ be continuous semigroups of nonexpansive mappings on C. Let $\left\{t_{n}\right\}$ and $\left\{q_{n}\right\}$ be sequences in $\mathbb{R}_{+}$. Let $\left\{\alpha_{n}\right\}$ and $\left\{\beta_{n}\right\}$ be sequences in $[0,1]$ with $0<$ $\alpha_{n}<1, \liminf _{n \rightarrow \infty} \beta_{n}\left(1-\beta_{n}\right)>0$. Suppose that $\Omega:=\left(\bigcap_{t \geq 0} F(T(t))\right) \cap\left(\bigcap_{q \geq 0} F(Q(q))\right) \neq \emptyset$. Let $\left\{x_{n}\right\}$ be defined as

$$
\left\{\begin{array}{l}
x_{1} \in C \quad \text { chosen arbitrary, } \\
y_{n}=\left(1-\beta_{n}\right) x_{n} \oplus \beta_{n} T\left(t_{n}\right) x_{n}, \\
x_{n+1}=\left(1-\alpha_{n+1}\right) Q\left(q_{n+1}\right) x_{n+1} \oplus \alpha_{n+1} y_{n} .
\end{array}\right.
$$

\section{Assume that}

(i) $\liminf _{n \rightarrow \infty} t_{n}<\limsup _{n \rightarrow \infty} t_{n}$;

(ii) either limsup $\operatorname{su}_{n \rightarrow \infty}\left(t_{n+1}-t_{n}\right) \leq 0$ or $\liminf _{n \rightarrow \infty}\left(t_{n+1}-t_{n}\right) \geq 0$ holds;

(iii) $\lim _{n \rightarrow \infty} q_{n}=\lim _{n \rightarrow \infty} \frac{\alpha_{n}}{q_{n}}=0$.

Then $\lim _{n \rightarrow \infty} x_{n}=\bar{x}$ for some $\bar{x} \in \Omega$.

Proof Take any $w \in \Omega$ and let $w$ be fixed. Then for each $n \in \mathbb{N}$,

$$
\begin{aligned}
& d\left(y_{n}, w\right)^{2} \\
& \quad=d\left(\left(1-\beta_{n}\right) x_{n} \oplus \beta_{n} T\left(t_{n}\right) x_{n}, w\right)^{2} \\
& \quad \leq\left(1-\beta_{n}\right) d\left(x_{n}, w\right)^{2}+\beta_{n} d\left(T\left(t_{n}\right) x_{n}, w\right)^{2}-\beta_{n}\left(1-\beta_{n}\right) d\left(x_{n}, T\left(t_{n}\right) x_{n}\right)^{2} \\
& \quad \leq\left(1-\beta_{n}\right) d\left(x_{n}, w\right)^{2}+\beta_{n} d\left(x_{n}, w\right)^{2}-\beta_{n}\left(1-\beta_{n}\right) d\left(x_{n}, T\left(t_{n}\right) x_{n}\right)^{2} \\
& \quad \leq d\left(x_{n}, w\right)^{2}
\end{aligned}
$$

and

$$
\begin{aligned}
& d\left(x_{n+1}, w\right)^{2} \\
& \quad=d\left(\left(1-\alpha_{n+1}\right) Q\left(q_{n+1}\right) x_{n+1} \oplus \alpha_{n+1} y_{n}, w\right)^{2}
\end{aligned}
$$




$$
\begin{aligned}
& \leq\left(1-\alpha_{n+1}\right) d\left(Q\left(q_{n+1}\right) x_{n+1}, w\right)^{2}+\alpha_{n+1} d\left(y_{n}, w\right)^{2}-\alpha_{n+1}\left(1-\alpha_{n+1}\right) d\left(Q\left(q_{n+1}\right) x_{n+1}, y_{n}\right)^{2} \\
& \leq\left(1-\alpha_{n+1}\right) d\left(x_{n+1}, w\right)^{2}+\alpha_{n+1} d\left(y_{n}, w\right)^{2}
\end{aligned}
$$

By (3.20) and (3.21),

$$
d\left(x_{n+1}, w\right) \leq d\left(y_{n}, w\right) \leq d\left(x_{n}, w\right) .
$$

Hence, $\lim _{n \rightarrow \infty} d\left(x_{n}, w\right)$ exists, $\lim _{n \rightarrow \infty} d\left(x_{n}, w\right)=\lim _{n \rightarrow \infty} d\left(y_{n}, w\right),\left\{x_{n}\right\}$ and $\left\{y_{n}\right\}$ are bounded sequences. By (3.20) and assumptions,

$$
\lim _{n \rightarrow \infty} d\left(x_{n}, T\left(t_{n}\right) x_{n}\right)=0 .
$$

By (3.21) and assumptions,

$$
\lim _{n \rightarrow \infty} d\left(Q\left(q_{n+1}\right) x_{n+1}, y_{n}\right)=0 .
$$

By (3.23) and (3.24), we have

$$
\lim _{n \rightarrow \infty} d\left(x_{n}, y_{n}\right)=0 \quad \text { and } \quad \lim _{n \rightarrow \infty} d\left(Q\left(q_{n+1}\right) x_{n+1}, x_{n+1}\right)=0 .
$$

Furthermore, by (3.23) and (3.25), it follows that

$$
\lim _{n \rightarrow \infty} d\left(T(0) x_{n}, x_{n}\right)=0 \quad \text { and } \quad \lim _{n \rightarrow \infty} d\left(Q(0) x_{n}, x_{n}\right)=0 .
$$

Following the same argument as in the proof of Theorem 3.1, there exist a subsequence $\left\{u_{n}\right\}$ of $\left\{x_{n}\right\}$ and $\bar{x} \in C$ such that $\lim _{n \rightarrow \infty} d\left(u_{n}, \bar{x}\right)=0$, and $\bar{x}$ is a common fixed point of $\{T(t): t \geq 0\}$. Hence, $\liminf _{n \rightarrow \infty} d\left(x_{n}, \bar{x}\right)=0$.

For $q=0$, by (3.26), we get $\lim _{n \rightarrow \infty} d\left(Q(0) u_{n}, u_{n}\right)=0$, and it is easy to see that $Q(0) \bar{x}=\bar{x}$.

Next, for each $q>0$,

$$
\begin{aligned}
& d\left(x_{n}, Q(q) \bar{x}\right) \\
& \leq d\left(x_{n}, Q(0) x_{n}\right)+\sum_{k=0}^{\left[\frac{q}{q_{n}}\right]-1} d\left(Q\left((k+1) q_{n}\right) x_{n}, Q\left(k q_{n}\right) x_{n}\right) \\
& \quad+d\left(Q\left(\left[\frac{q}{q_{n}}\right] q_{n}\right) x_{n}, Q\left(\left[\frac{q}{q_{n}}\right] q_{n}\right) \bar{x}\right)+d\left(Q\left(\left[\frac{q}{q_{n}}\right] q_{n}\right) \bar{x}, Q(q) \bar{x}\right) \\
& \leq d\left(x_{n}, Q(0) x_{n}\right)+\left[\frac{q}{q_{n}}\right] d\left(Q\left(q_{n}\right) x_{n}, x_{n}\right)+d\left(x_{n}, \bar{x}\right)+d\left(Q\left(q-\left[\frac{q}{q_{n}}\right] q_{n}\right) \bar{x}, Q(0) \bar{x}\right) \\
& \leq d\left(x_{n}, Q(0) x_{n}\right)+\frac{q \alpha_{n}}{q_{n}} d\left(Q\left(q_{n}\right) x_{n}, y_{n}\right)+d\left(x_{n}, \bar{x}\right)+\max \left\{d(Q(s) \bar{x}, Q(0) \bar{x}): 0 \leq s \leq q_{n}\right\} \\
& \leq d\left(x_{n}, Q(0) x_{n}\right)+\frac{q \alpha_{n}}{q_{n}} M+d\left(x_{n}, \bar{x}\right)+\max \left\{d(Q(s) \bar{x}, Q(0) \bar{x}): 0 \leq s \leq q_{n}\right\}
\end{aligned}
$$

for some $M>0$.

By assumptions and (3.26), we know that

$$
\limsup _{n \rightarrow \infty} d\left(u_{n}, Q(q) \bar{x}\right)=0
$$


for each $q>0$, and this implies that $\bar{x}$ is also a common fixed point of $\{Q(q): q \geq 0\}$. Now, $\bar{x} \in \Omega$ and this implies that $\lim _{n \rightarrow \infty} d\left(x_{n}, \bar{x}\right)$ exists. Since $\liminf _{n \rightarrow \infty} d\left(x_{n}, \bar{x}\right)=0$, we know that $\lim _{n \rightarrow \infty} d\left(x_{n}, \bar{x}\right)=0$, and the proof is completed.

Remark 3.3 Theorem 3.3 is also a generalization of Theorem 1.2.

The following result is similar to Theorem 2.3 in [27].

Corollary 3.1 Let $C$ be a nonempty compact convex subset of a complete CAT(0) space X. Let $\{Q(q): q \in \mathbb{R}\}$ be a continuous semigroup of nonexpansive mappings on $C$. Let $\left\{q_{n}\right\}$ be a sequence in $\mathbb{R}_{+}$. Let $\left\{\alpha_{n}\right\}$ be a sequence in $[0,1]$ with $0<\alpha_{n}<1$. Let $\left\{x_{n}\right\}$ be defined as

$$
\left\{\begin{array}{l}
x_{1} \in C \quad \text { chosen arbitrary, } \\
x_{n+1}=\left(1-\alpha_{n+1}\right) Q\left(q_{n+1}\right) x_{n+1} \oplus \alpha_{n+1} x_{n} .
\end{array}\right.
$$

Assume that $\lim _{n \rightarrow \infty} q_{n}=\lim _{n \rightarrow \infty} \frac{\alpha_{n}}{q_{n}}=0$. Then $\lim _{n \rightarrow \infty} x_{n}=\bar{x}$ for some $\bar{x} \in \Omega$.

Proof For each $t \geq 0$, let $T(t): C \rightarrow C$ be defined by $T(t) x:=x$ for each $x \in C$. Clearly, $\{T(t): t \geq 0\}$ is a continuous semigroup of nonexpansive mappings on $C$. Since $C$ is a compact set, $\Omega:=\bigcap_{q \geq 0} F(Q(q)) \neq \emptyset$. By Theorem 3.3, we get the conclusion.

\section{Competing interests}

The authors declare that they have no competing interests.

\section{Authors' contributions}

LJL: Problem resign, coordinator, discussion, revise the important part, and submit. CSC: Responsible for the important results of this paper, discuss, and draft. ZTY: Responsible for the results of this paper, discuss, and draft.

\section{Author details}

${ }^{1}$ Department of Mathematics, National Changhua University of Education, Changhua, 50058, Taiwan. ${ }^{2}$ Department of Electronic Engineering, Nan Kai University of Technology, Nantour, 54243, Taiwan.

\section{Acknowledgements}

This research was supported by the National Science Council of Republic of China.

Received: 15 February 2012 Accepted: 29 August 2012 Published: 18 September 2012

\section{References}

1. Kirk, WA: Geodesic geometry and fixed point theory. In: Seminar of Mathematical Analysis, Malaga/Seville, 2002/2003 Colección Abierta, vol. 64, pp. 195-225. University of Seville, Secretary of Publications, Seville (2003)

2. Kirk, WA: Geodesic geometry and fixed point theory. II. In: International Conference on Fixed Point Theory and Applications, pp. 113-142. Yokohama Publishers, Yokohama, Japan (2004)

3. Dhompongsa, S, Kaewkhao, A, Panyanak, B: Lim's theorems for multivalued mappings in CAT(0) spaces. J. Math. Anal. Appl. 312, 478-487 (2005)

4. Chaoha, P, Phonon, A: A note on fixed point sets in CAT(0) spaces. J. Math. Anal. Appl. 320, 983-987 (2006)

5. Leustean, L: A quadratic rate of asymptotic regularity for CAT(0)-spaces. J. Math. Anal. Appl. 325, 386-399 (2007)

6. Kirk, WA, Panyanak, B: A concept of convergence in geodesic spaces. Nonlinear Anal. 68, 3689-3696 (2008)

7. Bridson, MR, Haefliger, A: Metric Spaces of Non-Positive Curvature. Fundamental Principles of Mathematical Sciences, vol. 319. Springer, Berlin (1999)

8. Kirk, WA: Fixed point theorems in CAT(0) spaces and R-trees. Fixed Point Theory Appl. 2004, 309-316 (2004)

9. Goebel, K, Reich, S: Uniform Convexity, Hyperbolic Geometry, and Nonexpansive Mappings. Monographs and Textbooks in Pure and Applied Mathematics, vol. 83. Marcel Dekker, New York (1984)

10. Bruhat, F, Tits, J: Groupes reductifs sur un corps local. I. Donnees radicielles valuees. Publ. Math. IHÉS 41, 5-251 (1972)

11. Dhompongsa, S, Panyanak, B: On $\Delta$-convergence theorems in CAT(0) spaces. Comput. Math. Appl. 56, 2572-2579 (2008)

12. Kirk, WA: Krasnoselskii's iteration process in hyperbolic space. Numer. Funct. Anal. Optim. 4, 371-381 (1982)

13. Takahashi, W: A convexity in metric space and nonexpansive mappings I. Kodai Math. Semin. Rep. 22(2), 142-149 (1970)

14. DeMarr, R: Common fixed points for commuting contraction mappings. Pac. J. Math. 13, 1139-1141 (1963) 
15. Belluce, LP, Kirk, WA: Nonexpansive mappings and fixed-points in Banach spaces. III. J. Math. 11, 474-479 (1967)

16. Lim, TC: A fixed point theorem for families of nonexpansive mappings. Pac. J. Math. 53, 487-493 (1974)

17. Bruck, RE: A common fixed point theorem for a commuting family of nonexpansive mappings. Pac. J. Math. 53, 59-71 (1974)

18. Suzuki, T: An example for a one-parameter nonexpansive semigroup. Abstr. Appl. Anal. 2005(2), 173-183 (2005)

19. Youla, D: On deterministic convergence of iterations of related projection operators. J. Vis. Commun. Image Represent. 1, 12-20 (1990)

20. Byrne, C: A unified treatment of some iterative algorithms in signal processing and image reconstruction. Inverse Probl. 20, 103-120 (2004)

21. Shioji, N, Takahashi, W: Strong convergence theorems for asymptotically nonexpansive semi-groups in Hilbert spaces. Nonlinear Anal. 34, 87-99 (1998)

22. Suzuki, T: On strong convergence to common fixed points of nonexpansive semigroups in Banach spaces. Proc. Am. Math. Soc. 131, 2133-2136 (2003)

23. Zegeye, $\mathrm{H}$, Shahzad, N: Convergence theorems for strongly continuous semi-groups of asymptotically nonexpansive mappings. Nonlinear Anal. 71, 2308-2315 (2009)

24. Suzuki, T: Strong convergence of Krasnoselskii and Mann's type sequences for one-parameter nonexpansive semigroups without Bochner integrals. J. Math. Anal. Appl. 305, 227-239 (2005)

25. Dhompongsa, S, Fupinwong, W, Kaewkhao, A: Common fixed points of a nonexpansive semigroup and a convergence theorem for Mann iterations in geodesic metric spaces. Nonlinear Anal. 70, 4268-4273 (2009)

26. Cho, YJ, Ćirić, L, Wang, SH: Convergence theorems for nonexpansive semigroups in CAT(0) spaces. Nonlinear Anal. 74 6050-6059 (2011)

27. Thong, DV: An implicit iteration process for nonexpansive semigroups. Nonlinear Anal. 74, 6116-6120 (2011)

28. Dhompongsa, S, Kirk, WA, Sims, B: Fixed points of uniformly Lipschitzian mappings. Nonlinear Anal. 65, 762-772 (2006)

29. Dhompongsa, S, Kirk, WA, Panyanak, B: Nonexpansive set-valued mappings in metric and Banach spaces. J. Nonlinear Convex Anal. 8, 35-45 (2007)

30. Lin, LJ, Chuang, CS, Yu, ZT: Fixed point theorems and $\Delta$-convergence theorems for generalized hybrid mappings on CAT(0) spaces. Fixed Point Theory Appl. 2011, 49 (2011). doi:10.1186/1687-1812-2011-49

doi:10.1186/1687-1812-2012-155

Cite this article as: Lin et al.: Convergence theorems of common fixed points for some semigroups of nonexpansive mappings in complete CAT(0) spaces. Fixed Point Theory and Applications 2012 2012:155.

\section{Submit your manuscript to a SpringerOpen ${ }^{\ominus}$ journal and benefit from:}

- Convenient online submission

Rigorous peer review

- Immediate publication on acceptance

Open access: articles freely available online

- High visibility within the field

- Retaining the copyright to your article 